\title{
Characterization of the seismic behavior of steel pallet racks in cross-aisle direction
}

\author{
Catherine Braham ${ }^{1}$, Hervé Degée ${ }^{1,2}$ \\ ${ }^{1}$ Department ArGEnCo, Faculty of Applied Sciences, University of Liège, Chemin des Chevreuils, 1, 4000 Liège, Belgium \\ ${ }^{2}$ Construction Engineering Research Group, Faculty of Engineering Technology, Hasselt University, Agoralaan Gebouw H, \\ 3590 Diepenbeek, Belgium \\ email: c.braham@ulg.ac.be, herve.degee@uhasselt.be
}

\begin{abstract}
Stability of steel storage racks in the cross-aisle direction is typically ensured by cold-formed steel bolted upright frames with diagonal bracing. Accurately determining the shear behavior of these frames is essential for a proper seismic design and stability of the rack. In this paper, an experimental study of cross-frames designed to resist earthquake action is summarized. Structures are tested under transverse loading representative of the earthquake action, in static and cyclic conditions, with the objective of assessing the actual shear stiffness, shear resistance and deformation capacity of a set of earthquake-resistant crossframes with different bracing configurations. The work is part of a larger research project called Seisracks2 (Storage Racks in Seismic Areas) carried out at European level.
\end{abstract}

KEY WORDS: Storage racks; cross-aisle; frame behaviour, shear resistance.

\section{INTRODUCTION}

Racking systems are not regular buildings but a very particular form of steel construction. They differ from buildings in terms of their use, the loads that are supported, the geometrical dimensions and the components used in their construction. These components are normally thin-gauge coldformed profiles and, in the case of uprights, are typically continuously perforated. This gives the required functionality, adaptability and flexibility needed to cope with the great variation in the different types of goods that are stored.

Prediction of the structural behavior of pallet racks is difficult because affected by the particular geometry of their structural components, i.e. members made by high slenderness thin-walled elements hence prone to global, local and, for the uprights, distortional buckling problems. Moreover specific modeling and design rules are required for these nontraditional steel structures, especially for the beam-to-upright and base-plate joints in the down-aisle direction (Fig. 1) that exhibit a strongly non linear behavior. In the cross-aisle direction, stability is ensured by frames consisting of two uprights connected by bracing members as shown in Fig. 1.

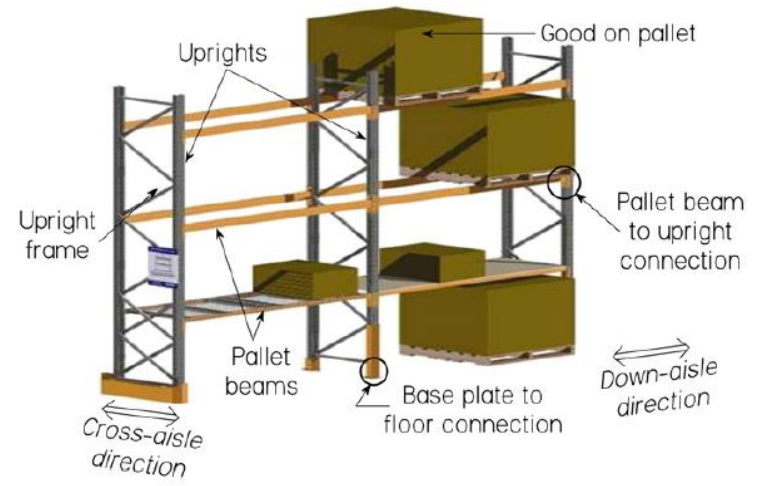

Figure 1. Typical storage rack configuration.
Design is even more complicated for storage racks installed in seismic zones, where they must be able to withstand horizontal and vertical dynamic forces and where, besides the usual global and local collapse mechanisms, additional limit states such as for instance the fall of the pallets with subsequent damage to goods, people and to the structure itself must be considered.

Whilst the basic technical description of an earthquake is obviously the same for all types of structures, it is of great importance to define whether or not it is possible to apply the "general design rules" (applicable to ordinary steel structures) to a rack. Furthermore it is necessary to consider how to modify correctly the general principles and technical requirements, in order to take into account the peculiarities of racking and to achieve the requested safety level. For instance, many specific physical phenomena strongly affect the structural behavior of a racking system during an earthquake, such as the energy dissipated in the deformation of stored goods or when pallets slide on their supports.

To this purpose, a working group had been initiated by the European Racking Federation. The main outcome of this working group is a new Code of Practice issued in September 2010 [8] and relying on a number of pre-existing standards. It includes also outcomes of the most recent researches carried out in Europe and the USA (see Ref. [9] for a comprehensive state of art and critical comment on FEM 10.2.08). In January 2011, the ERF working group has been converted into a CEN working group (within TC 344) with the aim of transposing the Code of Practice into a European standard EN. Alternatively, reference can be made to the Rack Manufacturers Institute (R.M.I.) specifications which include few pages proposing a way to account for seismic actions.

However, only a limited number of experimental results are available to cover these issues, which questions the reliability of the rules implemented in the various reference design procedures. 
Results presented in this paper are part of a wide research program "Seisracks2 - Storage Racks in Seismic Areas" funded by the European Union (RFCS research program). This research program aims at constituting a scientific background document for the conversion of the Code of practice FEM 10.2.08 to a European Standard and is intended to cover various items such as:

- The out-of-plane behavior of the beams and of the beam-to-upright connections;

- The actual structural behavior in cross-aisle direction depending on the geometrical configuration and on the type of connections of bracings between the uprights;

- The actual behavior in the down-aisle direction in presence of eccentric vertical bracings;

- The influence of the rate occupancy and of the location of the palletized goods;

- The reactions transferred to the concrete slab.

Within this project, these issues are planned to be investigated by means of component testing, full scale (pushover) testing and in-situ testing of racking systems in operating warehouses, all of these tests complemented by numerical simulations.

More specifically, the present paper intends to summarize the current situation of one of the main aspects of this research, namely the investigations carried out on the crossaisle behavior, with the objective of covering a wide range of configurations (D/Z/X type of cross bracing including different types of connection) and to investigate their consequences on the transverse stiffness, resistance and deformation capacity of the frame.

\section{TEST SETUP AND TEST SPECIMENS}

Independently of any seismic consideration, the European Standard EN 15512 [1] requires testing to evaluate the transverse stiffness per unit length of an upright frame. In the recommended test setup, shown in Fig. 2, an upright frame composed of at least two bracing panels is restrained in the transverse direction at two corners. One upright is pinned in the longitudinal direction at one end and a longitudinal load $\mathrm{F}$ is applied at the opposite end of the other upright through its centroidal axis. The exploitation of the experimental measurements consists then in determining the upright frame longitudinal shear stiffness and deriving then the transverse shear stiffness using Timoshenko and Gere's [2] shear formulae. It is generally considered that upright frames, braced with diagonal bracing members only, considering the full cross-section of the diagonals may lead to an overstimation of the shear stiffness by a factor up to 20 . The purpose of the test is thus to estimate the reduction of the diagonal cross-section to be used in further analysis. Finite element models developed in some studies available in the literature $[3,4,5]$ were also not really able to accurately reproduce the experimental test results and produced stiffness values that are 2 to 5 times greater than the observed results. The authors attribute the difference between FE results and experimental test results to the joint flexibility and the distortion of the upright, caused by the eccentricity between the uprights and the bracing members at the joints, which were not considered in the FE analysis.

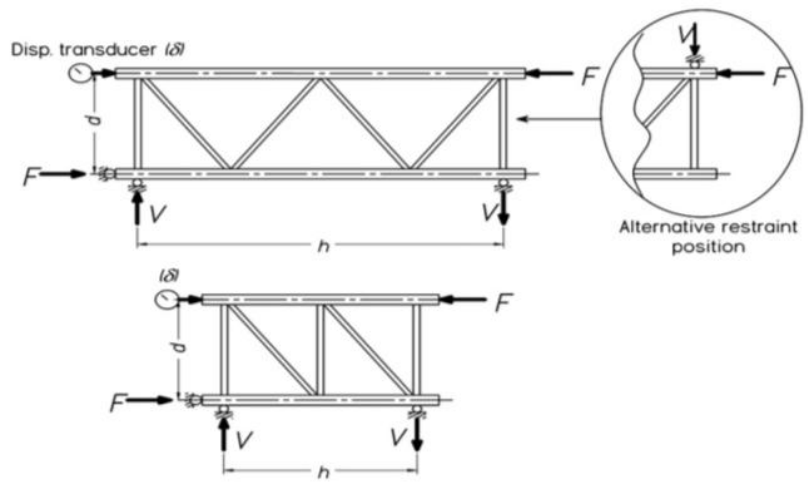

Figure 2. Upright frame shear stiffness setup in EN 15512 [1].

The EN 15512 test is however characterizing the behavior under pure shear, while the reality of the earthquake situation implies the combination of a shear loading varying over the height of the frame and combined with a significant overall bending contribution.

The purpose of the alternative test setup proposed in the present study is thus to focus on a more realistic loading procedure with the perspective of assessing the transverse stiffness, resistance and deformation capacity of cross-frames under realistic seismic loading conditions; the cross-frame tests are carried out on specimens similar to those classically used for the characterization of the pure shear behavior (although longer) but with an adapted loading. Tests are carried out statically ("pushover tests") and cyclically under transverse loading representative of the earthquake action.

Eurocode 8 [10] recommends that, when the fundamental mode shape is dominant, it can reasonably be approximated by horizontal modal displacements increasing linearly along the height. The associated horizontal forces $F_{\mathrm{i}}$ should be taken as being given by:

$F_{i}=F_{b} \frac{z_{i} m_{i}}{\sum z_{j} m_{j}}$

where:

$-z_{i}, z_{j}$ are the heights of the masses $m_{i}, m_{j}$ above the level of application of the seismic action (foundation or top of a rigid basement);

- $\mathrm{F}_{\mathrm{i}}$ is the horizontal force acting on storey $\mathrm{i}$;

- $F_{b}$ is the seismic base shear in accordance with expression (4.5) of Eurocode 8;

$-\mathrm{m}_{\mathrm{i}}, \mathrm{m}_{\mathrm{j}}$ are the storey masses computed in accordance with 3.2.4(2) of Eurocode 8.

Industrial partners involved in the project (4 European companies) were invited to provide at least one configuration out of the types suggested in Fig. 3 with the objective of getting a wide range of situations (design for low, moderate or high seismicity, D/Z/X type of cross bracing...). For confidentiality reasons the names of the Industrial partners are not given here nor the details of the profile sections, diagonalto-upright connection or upright to base-plate connection. 4 basic typologies have been selected regarding the geometrical 
pattern of the diagonals, as well as 4 types of diagonal-toupright connections, shown in Figure 3.
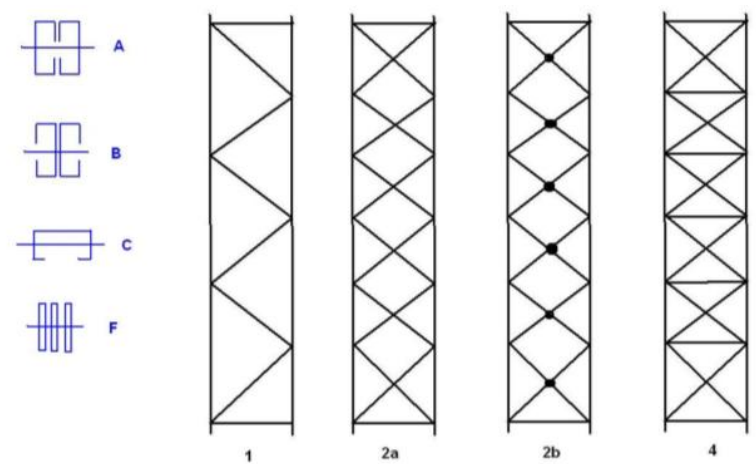

Figure 3. Typologies of upright frames.

In the standard shear test, a frame assembly with a minimum number of two bracing panels shall be connected to a rigid vertical column by pin-connecting the upright ends and tested horizontally for the ease of the execution, as reminded in Fig. 2. In the present study, a more realistic configuration has been chosen (although complicating the setup) consisting in 8 meter high frames tested transversally with 4 load levels equally distributed over the height of the frame with a constant spacing of $2 \mathrm{~m}$. These load levels correspond to the beam levels of the case-studies configurations, i.e. to levels where the masses are actually present. Vertical side guides are placed at each of these levels to prevent out-of-plane instabilities. The objective is clearly to test the frame in a real loading configuration in terms of shear and overall bending moment distribution.
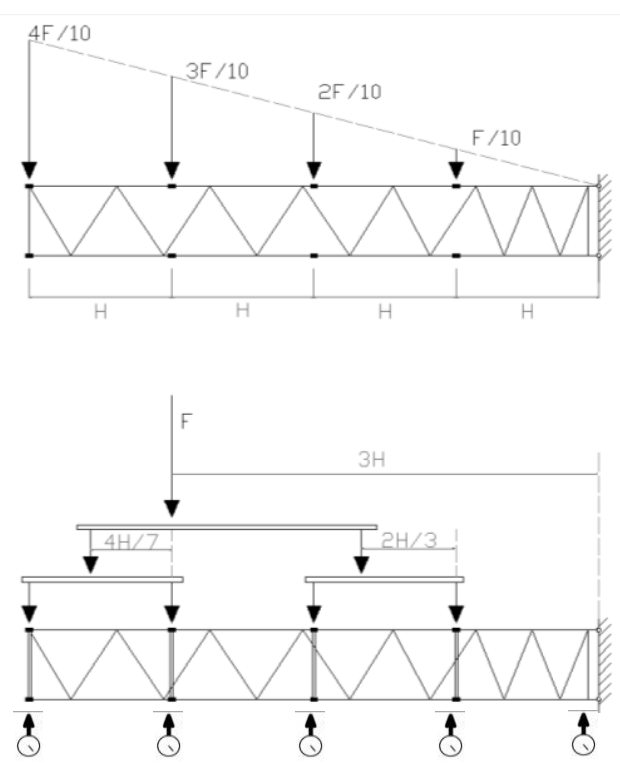

Figure 4. Test setup.

In practice, the loads are indirectly applied on the structure by means of one single jack $F$ acting on a distribution beam that is acting then on two other beams, in such a way that the support reactions of this two-levels loading system satisfy Eq. (1). Loads act directly on the upper side when pushing downwards; transfer hoops are foreseen to distribute the load to the lower upright when pulling. No direct axial force is applied on the uprights, implying the base connection to be designed, and if necessary reinforced appropriately to resist the tension induced by the overall bending of the system, in order to focus on a collapse in the main part of the frame and not in its connections to the floor. Displacement transducers are located next to the bottom horizontal bracing member and at each beam level. Two extra transducers measure the relative displacement between uprights at the first two beam levels.

Figure 5 depicts the 7 different configurations of crossframes to be tested with the corresponding diagonal's section. For confidentiality reasons no dimensions are revealed, nor of the bracing panels neither of the element cross-sections. For symmetric configurations (configs. 1, 4, 6 and 7), 1 pushover and 1 cyclic test are planned, whereas for asymmetric configurations, (configs. 2, 3 and 5), 2 pushover (one in each direction) and 1 cyclic test will be carried out.

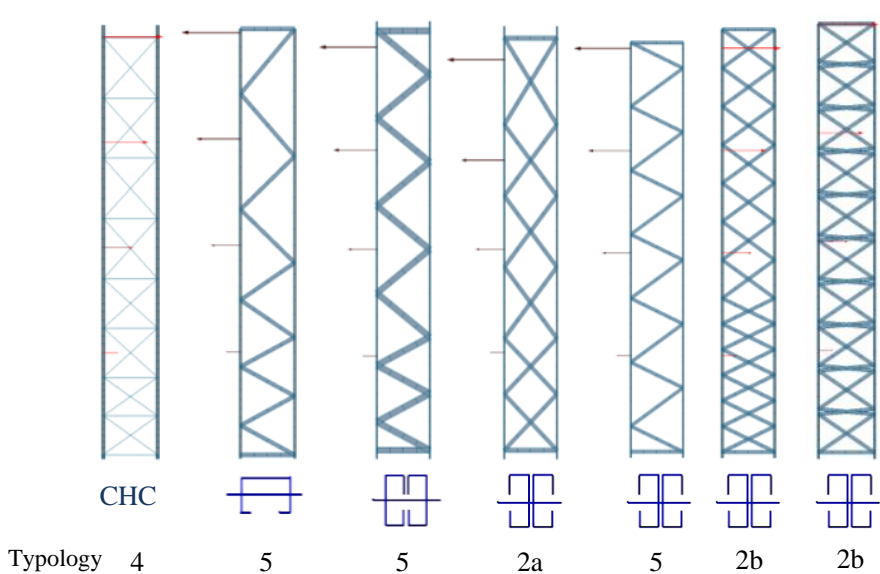

Figure 5. Tested configurations.

The behavior of the upright-to-base-plate connection is intended to be covered by the research project Seisracks 2 but with tests that are not discussed here. The aim of the study presented in this paper is specifically to emphasize on structural failure modes of the cross-frame either in the upright or in the bracing members but not in the upright-tobase-plate connection which is tested separately.

\section{TEST RESULTS}

As the present tests were meant to be realized without direct axial forces acting on the uprights the uprights-to-base-plate connections had to be reinforced in order to avoid an anticipated failure of these connections due to tension instead of decompression. Indeed the base connections are designed taking into account vertical efforts. Transversal load usually leads to extra compression in one connection and decompression in the other one which is not the case here. Uprights are therefore welded to the base-plates all along their profile, see Fig. 6 . 


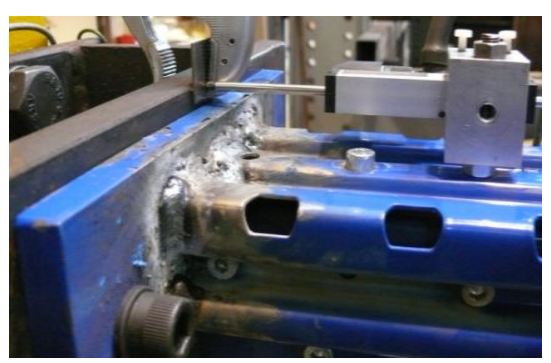

Figure 6. Upright welded to base-plate.

For confidentiality reasons towards the industrial Partners the results will not appear clearly in this paper; only the measurements of the top level are presented vs. the applied load but without units.

For symmetrical frames, the push-over load-displacement curves are represented as push and pull tests for comparison with the cyclic test, for which the specimens are subjected to a symmetrical reversed cyclic displacement history. Displacement history is expressed in terms of imposed displacement ductility, making reference to the yield displacement, generally evaluated through monotonic tests.

Testing procedure is composed by single fully reversed cycles at displacement ductility of $1 / 4,1 / 2,3 / 4$ and 1 , followed by a sequence of groups of two (or three) cycles at multiples (2, 3 , 4, etc.) of a yield displacement until a conventional failure criterion is met.

For the ease of the test-setup the cyclic tests have actually been load controlled. The tests are composed by single fully reversed cycles at $1 / 4,1 / 2$ and $3 / 4$ of the load at displacement ductility followed by a sequence of groups of 3 cycles at multiples of this load until a conventional failure criterion is met.

This procedure is sometimes adapted according to the measured displacements and the observations in order to avoid a premature failure.

\subsection{Test Series A.}

This cross-frame is designed for high seismic zone.

As seen on Fig. 7 this frame is relatively brittle, low energy can be dissipated and the ductility can be estimated equal to 1 .

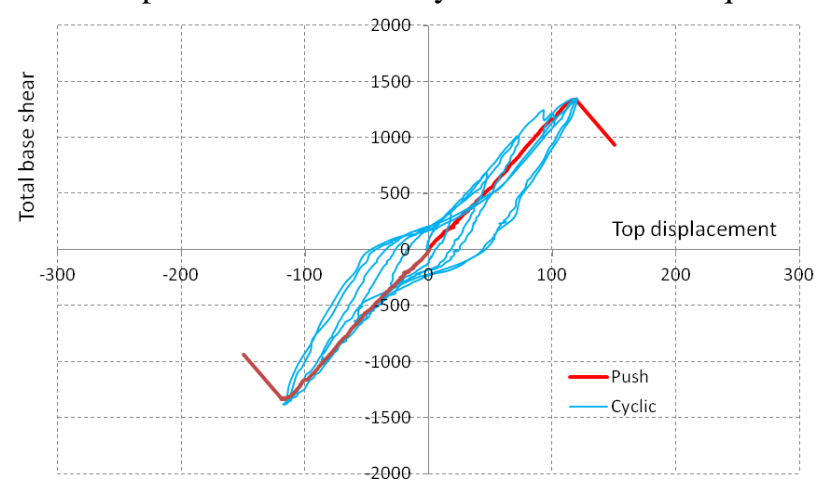

Figure 7. Force-displacement curve for test series A.

The failure modes are the following:

- local and global buckling of diagonal in compression;

- shearing of bolt of diagonal in tension.

\subsection{Test Series $B$.}

This cross-frame is designed for high seismic zone.

Both push-over tests fail at the same load level. The ductility lays around 1.75 .

The backbone curve of the cyclic test matches well with the monotonic tests.

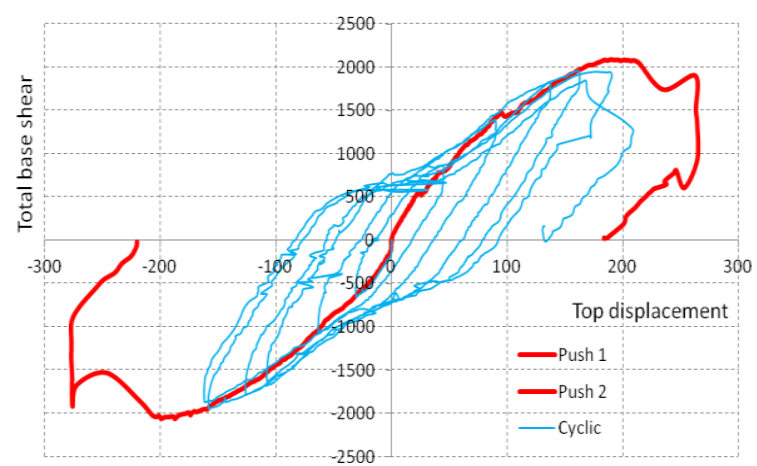

Figure 8. Force-displacement curve for test series B.

The failure modes observed are the following:

- local shear at diagonal intersection as they do not converge neither to the same connecting point nor to the centroid of the upright cross-section;

- diagonals remain intact.

The diagonals being connected to the uprights at different connection nodes leads to additional shear in the uprights between these 2 points which is fatal for the structure.

\subsection{Test Series $C$.}

This cross-frame is designed for moderate seismic zone.

The push-over curve in one direction matches perfectly the cyclic curve whereas the push-over curve in the other direction reaches higher loads with lower displacements. The reason of this might be because both push-over have been realised downwards and the cyclic down- and upwards leading to not symmetrical behaviour in terms of management of the looseness of the connections.

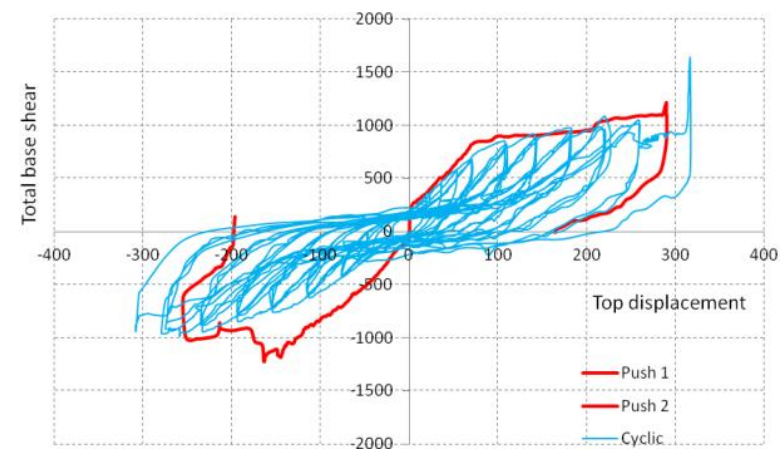

Figure 9. Force-displacement curve for test series C.

The failure modes are the following:

- bearing of diagonal in tension;

- buckling of diagonal in compression + local crushing of diagonal's extremities;

torsional buckling of uprights. 
According to both monotonic tests the ductility of this frame is expected between 1.4 and 1.6.

\subsection{Test Series D.}

This cross-frame is designed for high seismic zone.

The monotonic load-displacement curve fits perfectly the cyclic curve.

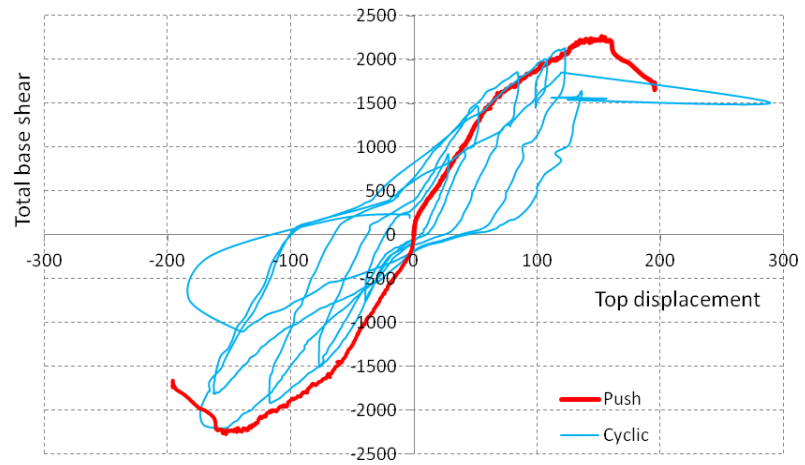

Figure 10. Force-displacement curve for test series D.

The failure modes are the following:

- $\quad$ buckling of diagonal in compression;

- bending of bolts;

- $\quad$ torsional buckling of uprights.

The ductility of this frame estimated according to the monotonic test is 1.79 which assumes the frame to be relatively energy dissipative.

\subsection{Test Series E.}

This cross-frame is designed for low seismic zone.

As the ductility estimated regarding both monotonic tests lays between 1.2 and 1.3 it was decided to cycle increasing the load progressively to avoid a premature failure during this test.

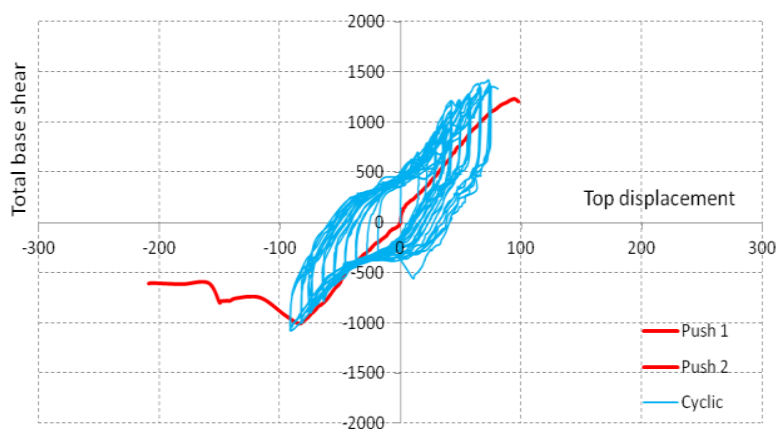

Figure 11. Force-displacement curve for test series E.

The vertical shift of the cyclic test in the positive values with regard to the monotonic is again due to the push downand upwards for the cyclic test whereas both monotonic are realised pushing downwards in relation with the looseness of the diagonal to upright connections.

The failure modes are the following:

- buckling of diagonal in compression;

- bearing of diagonal in tension.

\subsection{Test Series F}

This cross-frame is designed for moderate seismic zone.

The test in its designed configuration had to be stopped for a certain load level because the test setup would have been broken instead of the tested frame. The X-bracings being connected at mid-length makes this cross-frame very rigid and resistant. It remains almost in the elastic domain as shown on Fig. 12.

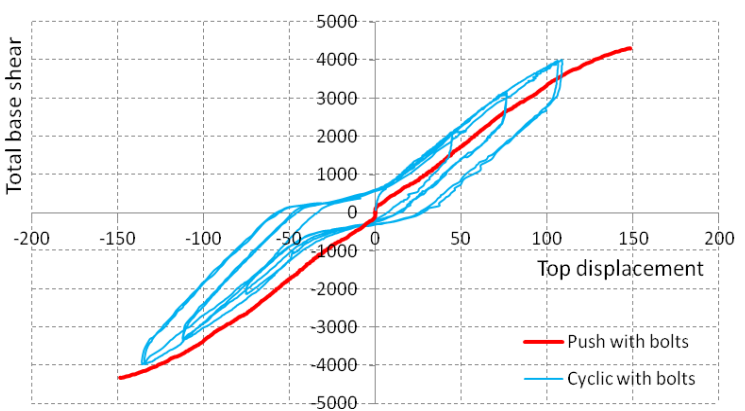

Figure 12. Force-displacement curve for test series F - with bolt.

The bolts connecting the diagonals at mid-length have thus been removed and the frame was retested; it finally failed at the same load level, see Fig. 13.

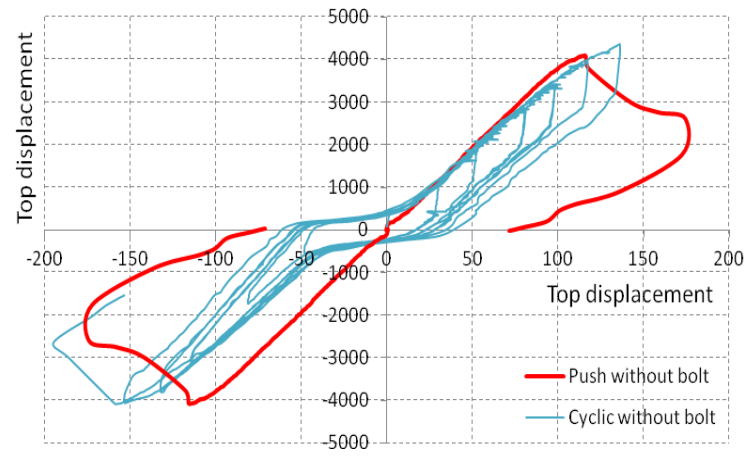

Figure 13. Force-displacement curve for test series $\mathrm{F}$ - without bolt.

The failure mode is the following:

- buckling of diagonals of all lower panels with a bend at mid-length.

The ductility of this frame is estimated at 1.3.

\subsection{Test Series G.}

This cross-frame is designed for high seismic zone.

The test had to be stopped before failure because of the stiffness of the frame due to the X-bracings connected at midlength. The applied load reached the maximum the test-setup could withstand.

The frame returned to its horizontal position, the bolts have been removed and the test reiterated. The load-displacement curves of both tests are illustrated in Figures 14 and 15. 


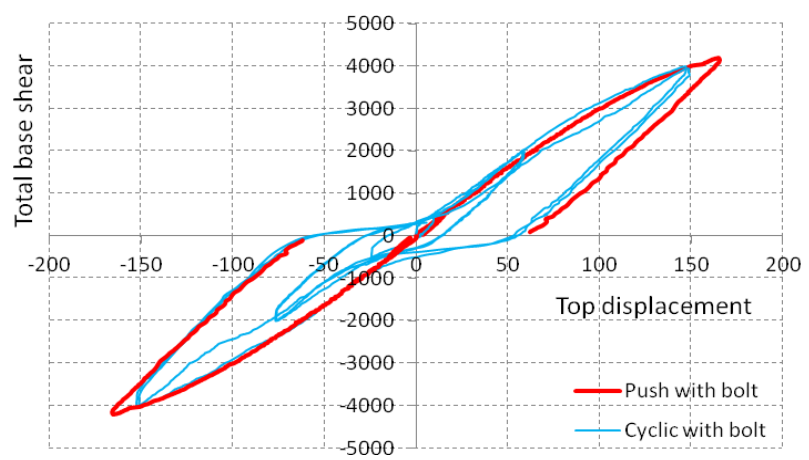

Figure 14. Force-displacement curve for test series G - with bolt.

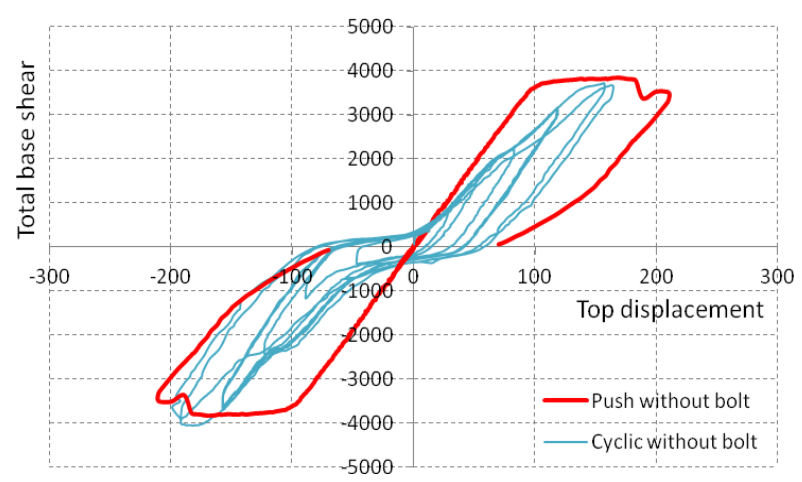

Figure 15. Force-displacement curve for test series G - without bolt.

The load-displacement curve of the unbolted cross-frame is a nice bi-linear curve followed by a regain in capacity. The ductility of this frame can be estimated at 2.1 .

The failure modes are the following:

- buckling of diagonals of lower panels;

- bearing of diagonals in tension.

\section{NUMERICAL RESULTS}

This second part of the paper aims at comparing the test results with a simple design-oriented numerical model and to calibrate it in order to match the test results. All tested crossframes have been modelled using a finite element analysis tool "FinelG" developed in the University of Liège in partnership with a design office established in Liège.

Uprights are defined as 2D beam elements and characterized by their cross-section and inertia. As the tests have all been realised with uprights welded to their base-plates this assumes a rigid connection.

Diagonals are considered as truss elements which are hinged at both ends to the uprights (without rotational stiffness). They are characterized by their cross-section and inertia.

Actual shear stiffness of the upright frame is affected by several factors (e.g. connection eccentricities, connections looseness, structural imperfection, bolt bending, local distortion of uprights), which are not normally considered in the conventional numerical analyses of racking structures. In order to take into account these factors that reduce considerably the overall stiffness compared to the one that can be obtained with simple structural models, a reduced value of area of bracing members is considered. This reduced crosssection is chosen in a way that it can change from one panel to the other respecting the same value for similar panels.

The following chapters detail for each cross-frame the diagonal's reduced section to consider such as to match the results measured during the test, and this for a given value of the base shear force chosen in the elastic domain.

These reduced sections are expressed in \% of the gross section of the diagonal given by the manufacturer. Crossframes have been modelled vertically; they are however illustrated in the tested configuration with the bottom on the left side.

\subsection{Test Series A.}

This cross-frame consists of four pairs of different bracing panels. It is thus logical to assign the same reduced section to the bracing members of one panel whatever the beam-level:

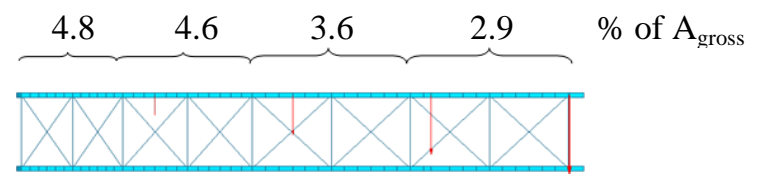

Figure 16. Numerical model for test series A.

As the bracing panels stretch out over the frame's height the cross-section of the bracing members have to be reduced to match the measured displacements. The top of the frame is more flexible, the stiffness and thus the area of the bracing members have to be reduced by almost half of the area of the bottom members and this in order to match the measured displacements.

\subsection{Test Series $B$.}

Only $2.2 \%$ of the net area can be considered for the bottom bracing members where they are tighter whereas the area can reach $5 \%$ of the net area for the top members who are less inclined:

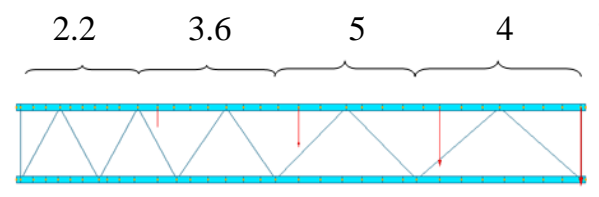

Figure 17. Numerical model for test series B.

The top of this frame needs to be stiffened in order to reduce the displacements.

\subsection{Test Series $C$.}

This cross-frame looks similar to the previous one as far as the modelling is concerned: $\mathrm{Z}$ type of cross bracing with panels that stretch from bottom to top. 


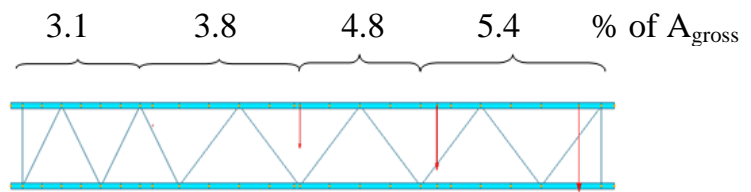

Figure 18. Numerical model for test series C.

\section{$4.4 \quad$ Test Series D.}

This symmetrical frame must be modelled with decreasing areas of the bracing members from bottom to top. The maximum expected percentage of the gross section is 3.4 .

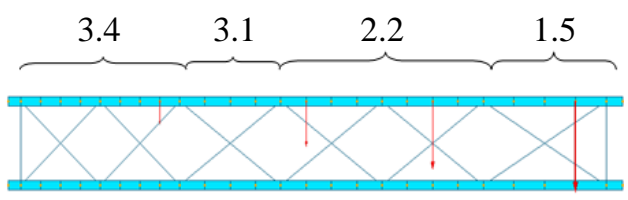

Figure 19. Numerical model for test series D.

\subsection{Test Series E.}

The panelling of this cross-frame is uniform over the height. A unique value of reduced area of the bracing members can be used with the result of getting the measured displacements:

12.4

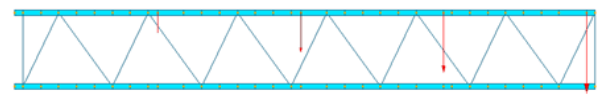

Figure 20. Numerical model for test series E.

This considered portion of area of the bracing members is far higher than for the previous tests. Is it due to the homogeneity of the bracing panels or just because of a good combination upright/diagonal's geometries of the manufacturer?

\subsection{Test Series F.}

The model has been realised and compared in the unbolted version. Although the panelling is not uniform along the height of the cross-frame the model has been realised with one unique value of the reduced cross-section for all bracing members.

13.3 $\%$ of $\mathrm{A}_{\text {gross }}$

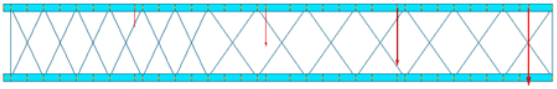

Figure 21. Numerical model for test series F.

Here again the expected percentage of bracing cross-section is high compared to the first series; the value of the reduced area of the diagonals corresponds to $13.3 \%$ of their gross section.

\subsection{Test Series $G$.}

This cross-frame is unusual concerning its typology which could be seen as a mixture of $2 \mathrm{a}$ and 4 in Fig. 3. All bracing members have the same geometry, only the panelling is changing, alternatively one tight and one stretched.

The reduced area of the bracing members can be taken equal over the frame's height in order to match the measured displacements; this area corresponds to $13.3 \%$ of the gross area of the diagonals which is a significant value.

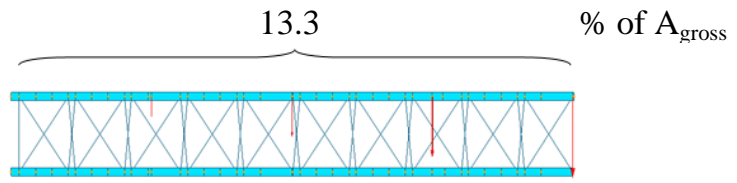

Figure 22. Numerical model for test series G.

\subsection{Summary}

The numerical models consider reduced values of area of bracing members in order to match the displacements measured during the elastic phase of the test.

The table here below summarizes these values of area (in \% of the gross area) of the bracing members considered for each tested cross-frame, between beam-levels respecting the panelling of the frames.

Table 1: Effective area of bracing members in $\%$ of $\mathrm{A}_{\text {gross }}$.

Diagonal section [\% of $A_{\text {gross }}$ ]

\begin{tabular}{ccccc} 
Test Series & $1^{\text {st }}$ level & $2^{\text {nd }}$ level & $3^{\text {rd }}$ level & $4^{\text {th }}$ level \\
\hline A & 4.8 & 4.6 & 3.6 & 2.9 \\
B & 2.2 & 3.6 & 5 & 4 \\
C & 3.1 & 3.8 & 4.8 & 5.4 \\
D & 3.4 & 3.1 & 2.2 & 1.5 \\
E & 12.4 & 12.4 & 12.4 & 12.4 \\
F & 13.3 & 13.3 & 13.3 & 13.3 \\
G & 13.3 & 13.3 & 13.3 & 13.3 \\
\hline
\end{tabular}

The calibration of the models does not allow drawing any general conclusion: the reduced values of area of bracing members sometimes need to be increased over the height of the cross-frames, sometimes have to decrease or can even remain constant, whatever the typology or symmetry. This seems to be product-specific and highly related to the type of connection of the bracings and to the possible cross-section deformability of the uprights.

Nevertheless there seems to be a common tendency for unsymmetrical frames to show out reduced values of area of the bracing members higher on the top than at the bottom of the frame while symmetrical frames suggest the opposite (except case series E, F and G which consider the same value for all bracing members, certainly due to tighter connections and cross-sectionally stiffer uprights). 
5 CONCLUSIONS

This paper has presented the general headlines of a study that aims at investigating the behavior of cross frames of pallet racks under earthquake loading. More specifically, the paper presents the results of monotonic and cyclic tests realized on cross-frames with different typologies of diagonal-to-upright connections and geometrical pattern of the bracing members.

In parallel to these tests, simple elastic numerical analyses of all frames have been performed in the perspective of calibrating the stiffness of the bracing members. The reduction of the cross-sectional area of the diagonals calibrated to match with the tests described in this paper could be further compared with the values obtained from standard shear tests, which is however of no ease because they should be modulated according to the paneling of the structural system. Indeed the standard shear tests advocate a number of two bracing panels, which in general are identical, whereas the present cross-frames are 8 meters long with a minimum of 5 bracing panels which often stretch over the height of the frame. Furthermore the tested combination upright-diagonal regarding the geometrical properties as well as the paneling do not match with those used in the standard test such as the comparison would just be approximate.

Thanks to the large variety of cross-frames tested, an interesting experimental data base has been elaborated, with measured ductilities varying according to the different active failure modes. Resulting values are summarized in the following table:

Table 2: Measured ductility with corresponding failure modes.

\begin{tabular}{llr}
\hline & \multicolumn{1}{c}{ Failure mode } & \multicolumn{1}{c}{ Ductility } \\
\hline A & Diagonal: buckling + shearing of bolts & 1,01 \\
B & Upright: local shear & 1,75 \\
C & Diagonal: buckling + local crushing & \\
& Upright: torsional buckling & $1,40 / 1,63$ \\
D & Diagonal: buckling + bending of bolts & \\
& Upright: torsional buckling & 1,79 \\
E & Diagonal: buckling + bearing & $1,33 / 1,18$ \\
F & Diagonal: buckling & 1,27 \\
G & Diagonal: buckling + bearing & 2,06 \\
\hline
\end{tabular}

For what regards the stiffness assessment, and in order to take into account several factors - such as connection properties, imperfections or local weaknesses of upright and bracing members - which reduce considerably the overall stiffness compared to the one that can be obtained with direct simple structural models, a reduced value of the crosssectional area of the bracing members is calibrated for each of the configurations of cross-frames considered in the study. This reduced cross-section is chosen in a way that it is likely to change from one panel to the other, keeping however a same value for similar panels. It is expressed as a percentage of the net cross section of the bracing member.
According to the tests illustrated in this report, it is expected to rely on a net cross section of the bracing members ranging hardly between $2,2 \%$ and $13,3 \%$ of their gross cross-section. Symmetric frames can be modelled with higher cross-sections at the bottom than at the top whereas asymmetric frames have to be modelled by increasing the reduced cross-section up to the top; some frames allow the same reduced cross-section over the height whatever the symmetry.

\section{ACKNOWLEDGMENTS}

Support for this research from the European Commission, Research Fund for Coal and Steel, Steel Technical Group TGS 8 "Steel products and applications for building, construction and industry", is gratefully acknowledged. H. Degée also acknowledges the support received from F.R.S.FNRS.

\section{REFERENCES}

[1] EN 15512. Steel static storage systems - adjustable pallet racking systems - principles for structural design. Brussels, Belgium: European Committee for Standardization (CEN); 2009.

[2] Timoshenko SP, Gere JM.Theory of elastic stability. $2^{\text {nd }}$ edition. New York, USA: McGraw-Hill Book Company, Inc; 1961.

[3] Sajja SR, Beale RG, Godley MHR. Factors affecting the shear stiffness of pallet rack uprights. In: Camotim D, et al, editor. Stability and ductility of steel structures, Lisbon, Portugal; 2006. P. 365-72.

[4] Sajja SR, Beale RG, Godley MHR. Shear stiffness of pallet rack upright frames. J Constr Steel Res 2008; 64:867-74.

[5] Godley MHR, Beale RG. Investigation of the effects of looseness of bracing components in the cross-aisle direction on the ultimate loadcarrying capacity of pallet rack frames. Thin-Walled Struct; 2008;46:84854.

[6] Gilbert B.P., Rasmussen K.J.R., Baldassino N, Cudini T, Rovere L. Determining the transverse shear stiffness of steel storage rack upright frames. Journal of Constructional Steel Research; 78(2012): 107-116.

[7] Degée H, Denoël V. Numerical modeling of storage racks subjected to earthquake. ECCOMAS Thematic Conference on Computational Methods in Structural Dynamics and Earthquake Engineering, Rethymno, Crete, Greece; 2007.

[8] FEM 10.2.08 - "Recommendations for the design of static steel racks in seismic conditions", version 1.00, European Racking Federation, September 2010.

[9] Degée H. New European recommendations for the design of static steel pallet racks in seismic conditions - the FEM 10.2.08 Code of Practice. Proc. of the ICTWS 2011 Conference, Timisoara (2011).

[10] EN 1998 - Eurocode 8 - "Design of structures for earthquake resistance", CEN, 2005. 